To Maega | Jurnal Pengabdian Masyarakat

Februari 2022, Vol.5, No.1, hal, 84-90

$\operatorname{ISSN}(P): 2622-6332 ; \operatorname{ISSN}(E): 2622-6340$

http://www.ojs.unanda.ac.id/index.php/tomaega

\title{
Pemanfaatan Virtual Meeting dan YouTube dalam Meningkatkan Pengetahuan Konsumsi Sayur Masyarakat Indonesia
}

\author{
Linda Riski Sefrina ${ }^{{ }^{*}}$, Al Mukhlas Fikri ${ }^{1}$ \\ ${ }^{1}$ Program Studi Gizi, Fakultas Ilmu Kesehatan, Universitas Singaperbangsa Karawang \\ *Correspondent Email: linda.riski@fkes.unsika.ac.id \\ Article History: \\ Received: 16-12-2021; Received in Revised: 22-12-2021; Accepted: 11-01-2022 \\ DOI: http://dx.doi.org/10.35914/tomaega.v5i1.962
}

\begin{abstract}
Abstrak
Berdasarkan survei nasional perilaku konsumsi sayur masyarakat Indonesia masih rendah, baik dari frekuensi maupun jumlah. Rendahnya perilaku konsumsi sayur berpengaruh pada kejadian obesitas. Angka obesitas di Indonesia masih terus meningkat di setiap tahunnya. Salah satu faktor resiko yang dapat diubah untuk mencegah terjadinya obesitas adalah memperbaiki perilaku konsumsi. Perilaku tersebut dipengaruhi oleh pengetahuan tentang sayur, manfaat dan cara pengolahannya yang rendah. Oleh karena itu, tujuan dari kegiatan pengabdian masyarakat ini adalah untuk meningkatkan pengetahuan masyarakat tentang pentingnya konsumsi sayur masyarakat Indonesia. Kegiatan pengabdian masyarakat ini dikemas dalam bentuk suatu webinar yang disiarkan langsung melalui Zoom Cloud Meeting dan livestream YouTube. Kegiatan webinar ini diikuti oleh 85 peserta dari berbagai kalangan profesi serta masyarakat umum. Materi yang diberikan antara lain adalah manfaat konsumsi sayur dan cara mengolah sayur menjadi menu yang enak dengan cara mudah. Berdasarkan hasil kuesioner pre-test dan post-test, sebagian besar peserta memahami materi webinar dan memiliki peningkatan pengetahuan gizi terkait sayur.
\end{abstract}

Kata Kunci: webinar, daring, pengetahuan, konsumsi sayur

\begin{abstract}
Based on a national survey, the vegetables consumption of Indonesian were still low. Previous studies showed that low consumption of vegetables were related to obesity. The prevalence of obesity in Indonesia increase each year. One of the risk factors that modifiable to prevent obesity is dietary. This behavior was affected by knowledge about vegetables, their benefits and the cooking methods. Therefore, the purpose of this community service was to increase knowledge of the vegetable consumption among Indonesian people. This community service was a webinar, that was live broadcasted through Zoom Cloud Meeting and YouTube. This webinar was attended by 85 participants from various audience. The material of this webinar explained the benefits of consuming vegetables and how to cook vegetables become a delicious meal in an easy way. Based on the results of the pre-test and post-test questionnaires, most of the participants understood the webinars' material and had increased knowledge of nutrition related to vegetables.
\end{abstract}

Keywords: webinar, online, knowledge, vegetable consumption 

Vol.5; No.1; Februari 2022

\section{Pendahuluan}

Masalah kesehatan di dunia terkait obesitas masih mengalami peningkatan setiap tahunnya. Obesitas merupakan salah satu faktor resiko dari berbagai penyakit tidak menular seperti hipertensi, diabetes melitus, penyakit kardiovaskuler, dan kanker. Seseorang dikategorikan obesitas apabila memiliki Indeks Massa Tubuh (IMT) $\geq 30 \mathrm{~kg} / \mathrm{m}^{2}$. Di tingkat dunia, pada tahun 2016 terdapat peningkatan penderita obesitas sebesar 50\% dibandingkan tahun 2000 (WHO, 2021). Berdasarkan Riset Kesehatan Dasar tahun 2018, prevalensi obesitas terus mengalami peningkatan dari tahun 2007 sebesar 10,5\% menjadi 14,8\% pada tahun 2013, dan meningkat pada tahun 2018 menjadi sebanyak 21,8\% (Balitbangkes, 2018).

Peningkatan prevalensi obesitas dipengaruhi oleh kuantitas dan kualitas konsumsi seseorang (Vergnaud et al., 2012). Salah satu perilaku yang beresiko menimbulkan obesitas adalah perilaku konsumsi makanan yang tidak seimbang, sehingga tidak sesuai dengan kebutuhan harian setiap individu (Siahaan \& Yuwono, 2021). Penderita obesitas cenderung mengkonsumsi makanan tinggi energi, gula dan berlemak tapi rendah dalam mengkonsumsi sayur. Berdasarkan SKMI 2014, konsumsi sayur masyarakat Indonesia hanya sebesar 57,1 gram per hari (Balitbangkes, 2014). Jumlah tersebut jauh lebih rendah dibandingkan dengan kebutuhan yang tertulis dalam Pedoman Gizi Seimbang (2014) yaitu sebesar 250 gram per hari (Kemenkes, 2014).

Penelitian Vergnaud et. al., (2012) menunjukkan terdapat potensi konsumsi sayur dengan pencegahan obesitas. Sayuran merupakan bahan pangan dengan kandungan energi yang rendah dan kandungan serat yang tinggi. Kandungan serat dalam sayuran memberikan rasa kenyang yang lebih cepat pada saat makan dan rasa kenyang tersebut dapat bertahan lebih lama dibandingkan dengan makanan tinggi kalori (Clark \& Slavin, 2013; He et al., 2004).

Selain itu, konsumsi sayur juga mampu menurunkan resiko Penyakit Tidak Menular (PTM). Konsumsi sayur mampu menurunkan resiko 14\% pada penyakit jantung koroner (Gan et al., 2015). Konsumsi sayur dan buah-buahan 5 porsi per hari dianjurkan untuk mengurangi risiko penyakit kardiovaskular (CVD). Hal ini berkaitan dengan zat gizi yang dikandung oleh sayuran, yaitu melalui kombinasi menguntungkan dari mikronutrien, antioksidan, fitokimia, dan serat mampu mencegah timbulnya kerusakan sel dan jaringan di dalam tubuh (He et al., 2004).

Kebiasaan yang tidak sehat dipengaruhi oleh pengetahuan gizi dan kesehatan yang rendah (Spronk et al., 2014). Beberapa penelitian menunjukkan bahwa perilaku konsumsi dapat dipengaruhi oleh pengetahuan gizi yang masih rendah. Pendidikan gizi merupakan salah satu cara untuk mengatasi pengetahuan gizi yang rendah. Program pendidikan gizi dirancang untuk meningkatkan pengetahuan gizi, sehingga para peserta mampu memperbaiki dan meningkatkan konsumsi makanan sehat seperti sayur (Mulyani et al., 2020; Saraswati \& Dieny, 2012). Sebelum pandemi covid-19, kegiatan pendidikan gizi dilaksanakan dengan tatap muka secara langsung tapi setelah pandemi covid-19, kegiatan ini banyak mengalami perubahan 
mekanisme pelaksanaan, salah satunya dengan webinar atau web seminar. Perubahan tersebut dilakukan sebagai bentuk adaptasi kebiasaan baru selama pandemi covid-19. Oleh karena itu, kegiatan pengabdian masyarakat ini memiliki tujuan untuk meningkatkan pengetahuan gizi terutama tentang sayur dan pengolahannya.

\section{Metode}

Kegiatan pengabdian masyarakat ini merupakan kegiatan pendidikan gizi yang menggunakan metode penyuluhan secara daring. Acara ini merupakan seminar online atau webinar yang dilakukan melalui penyampaian materi oleh narasumber, kemudian dilanjutkan dengan sesi tanya jawab. Kegiatan ini dilaksanakan pada tanggal 13 November 2021 pada pukul 10.00-12.30 WIB diikuti oleh 85 peserta dari berbagai profesi di seluruh Indonesia. Webinar ini disiarkan langsung melalu Zoom Cloud Meeting dan YouTube.

Kegiatan ini penting agar masyarakat mendapatkan wawasan yang lebih dalam dan luas terkait manfaat konsumsi sayur. Selain itu, narasumber juga menyampaikan jumlah kebutuhan konsumsi dalam sehari dan bagaimana cara mengolah sayur menjadi menu makanan yang mudah, lezat dan bergizi. Webinar ini dilaksanakan dalam beberapa tahap yaitu tahapan penyusunan tim pelaksana, perancangan kegiatan, publikasi dan promosi kegiatan, pelaksanaan kegiatan, dan tahap pembuatan laporan hasil kegiatan. Perancangan kegiatan dilakukan sejak 3 bulan sebelum pelaksanaan. Kegiatan ini melibatkan kepanitiaan yang terdiri dari dosen dan mahasiswa Program Studi Gizi Universitas Singaperbangsa Karawang.

Pada webinar ini dilakukan pengambilan data untuk mengetahui peningkatan pengetahuan gizi peserta. Penilaian perubahan perngetahuan menggunakan kuesioner pre-test dan post-test online selama acara berlangsung. Komponen yang ditanyakan dalam kuesioner tersebut antara lain adalah manfaat sayur bagi tubuh, teknik-teknik pengolahan sayur dan dasar modifikasi menu makanan berbahan sayur. Pengetahuan dikategorikan menjadi 3 tingkat yaitu "rendah" apabila jawaban benar $<60 \%$, "sedang" apabila jawaban benar 60-80\%, dan "baik" apabila jawaban benar $>80 \%$ (Khomsan et al., 2009). Analisis data yang dilakukan adalah analisis deskriptif yang dilakukan menggunakan Ms. Excel 2019. Selanjutnya, penyajian data hasil analisis dalam artikel ini disajikan dalam grafik dan persentase.

\section{Hasil dan Pembahasan}

Kegiatan webinar ini bertujuan untuk mengedukasi masyarakat tentang pentingnya konsumsi sayur dan memperbaiki persepsi masyarakat terutama yang konsumsi sayurnya masih rendah. Kegiatan webinar ini diikuti oleh sebanyak 85 peserta. Jumlah dan jenis sayuran yang sebaiknya dikonsumsi oleh masyarakat Indonesia telah terdapat di Pedoman Gizi Seimbang tahun 2014. Sesuai dengan pedoman tersebut, masyarakat Indonesia perlu mengonsumsi sayuran sebanyak 250 
[ 87 ] Linda Riski Sefrina \& Al Mukhlas Fikri / To Maega : Jurnal Pengabdian Masyarakat, Vol.5; No.1; Februari 2022

gram per hari (Kemenkes, 2014). Tetapi, pada faktanya berdasarkan Riskesdas tahun 2018 sebanyak 95,5\% penduduk Indonesia kurang konsumsi sayur (Balitbangkes, 2018).

Tabel 1. Perbandingan Pengetahuan Gizi Peserta

\begin{tabular}{lcccc}
\hline Kategori Pengetahuan & \multicolumn{2}{c}{ Pre-test } & \multicolumn{2}{c}{ Post-test } \\
\cline { 2 - 5 } & n & \% & n & \% \\
\hline Kurang & 51 & 60,0 & 3 & 3,5 \\
Sedang & 30 & 35,3 & 32 & 37,6 \\
Baik & 4 & 4,7 & 50 & 58,8 \\
\hline Total & $\mathbf{8 5}$ & $\mathbf{1 0 0 , 0}$ & $\mathbf{8 5}$ & $\mathbf{1 0 0 , 0}$ \\
\hline
\end{tabular}

Penelitian menunjukkan bahwa terdapat beberapa faktor yang mempengaruhi individu tidak mengkonsumsi sayur antara lain adalah pengetahuan yang masih rendah, anggapan sayur adalah makanan yang tidak enak, dan menu sayuran yang membosankan (Hariati, 2021). Oleh karena itu materi dalam kegiatan ini disesuaikan dengan permasalahan tersebut.

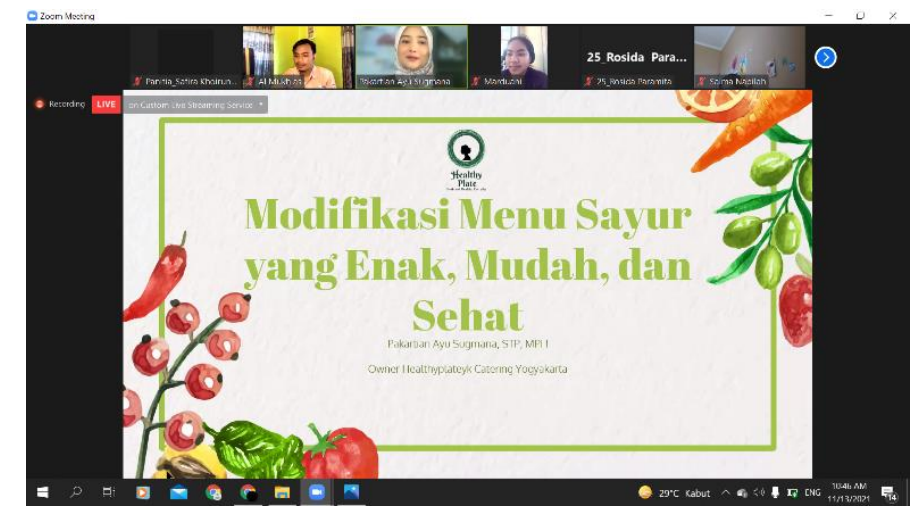

Gambar 1. Pelaksanaan Kegiatan melalui Zoom Cloud Meeting

Ada beberapa hal penting yang perlu diperhatikan dalam pengolahan sayur, yaitu menghindari penggunaan alat yang dapat berkarat atau bereaksi dengan makanan seperti besi tuang atau cor, mencuci sayur terlebih dahulu sebelum dipotong-potong kecil, merebus sayur pada saat air sudah mendidih agar tidak banyak zat gizi yang berkurang karena larut dalam air, serta gunakan sedikit air pada sayuran dengan waktu pemasakan yang tidak terlalu lama untuk mengurangi hilangnya vitamin C. Selain itu, pada webinar ini juga disampaikan modifikasi menu-menu makanan berbahan sayur dengan harapan dapat diterapkan oleh para peserta dalam kehidupan sehari-hari.

Pendidikan gizi terbukti memiliki dampak yang positif terhadap peningkatan konsumsi sayur (Spronk et al., 2014). Hal ini berkaitan dengan kemampuan kegiatan pendidikan memperbaiki pengetahuan, motivasi dan kesadaran audiens tentang konsumsi sayur. Hasil penelitian tersebut sejalan dengan hasil dari kegiatan ini yang disajikan dalam Tabel 1. Tabel 1 menunjukkan bahwa persentase peserta 
[ 88 ] Linda Riski Sefrina \& Al Mukhlas Fikri / To Maega : Jurnal Pengabdian Masyarakat, Vol.5; No.1; Februari 2022

yang memiliki pengetahuan baik meningkat dari $4,7 \%$ menjadi $58,8 \%$ dan pengetahuan sedang dari $35,3 \%$ menjadi $37,6 \%$. Hasil ini menunjukkan bahwa terdapat peningkatan pengetahuan gizi pada sebagian besar peserta webinar. Hasil ini sesuai dengan kegiatan pengabdian masyarakat yang dilakukan oleh Yunita et.al (2021) yang menunjukkan terdapat peningkatan pengetahuan pada para peserta setlah diberikan penyuluhan secara daring (Atmadani et al., 2021).

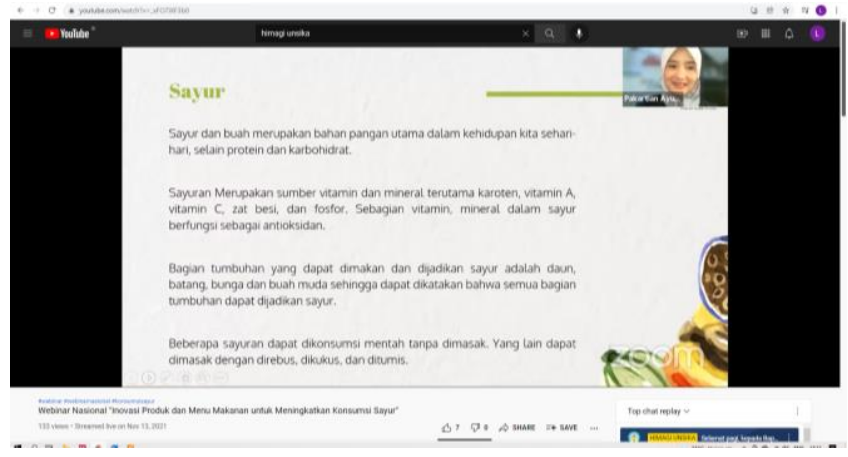

Gambar 2. Pelaksanaan Kegiatan melalui Live Streaming YouTube

Sejak ditemukannya Covid-19 pada tahun 2019 hingga dinyatakan sebagai pandemi, banyak sektor kehidupan manusia yang terkena dampak. Dampak tersebut salah satunya dirasakan dalam kehidupan sosial manusia akibat physical distancing. Physical distancing atau pembatasan interaksi sosial yang diterapkan untuk menekan penyebaran penularan Covid-19. Selama pandemi covid-19, terdapat keterbatasan pada pelayanan kesehatan, salah satunya adalah pendidikan gizi. Oleh karena itu, perlu adanya modifikasi kegiatan pendidikan gizi yang sesuai dengan adaptasi kebiasaan baru pada saat pandemi covid-19. Webinar merupakan salah satu kegiatan pendidikan secara digital yang dapat mencakup sasaran yang luas dan cost-effectiveness yang baik (Power \& St-Jacques, 2014).

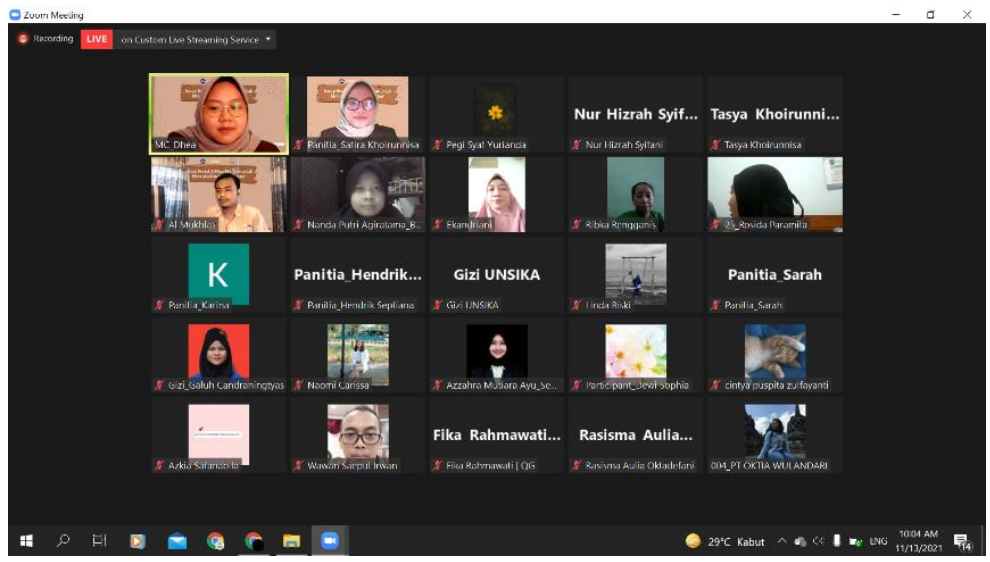

Gambar 3. Foto Peserta Kegiatan melalui Zoom Meeting

Pelaksanaan kegiatan pendidikan gizi yang menggunakan platform digital ini tentu menemui hambatan. Salah satu hambatan kegiatan yang sulit dikendalikan 
[ 89] Linda Riski Sefrina \& Al Mukhlas Fikri / To Maega : Jurnal Pengabdian Masyarakat, Vol.5; No.1; Februari 2022

adalah keterbatasan sinyal internet, karena para peserta berasal dari berbagai kota di Indonesia, sehingga beberapa kali harus ada pengulangan informasi yang diberikan. Secara garis besar, acara ini dapat dilaksanakan dengan lancar. Meskipun terdapat hambatan-hambatan yang terjadi, masih dapat ditangani selama acara berlangsung.

\section{Kesimpulan}

Pelaksanaan kegiatan pengabdian kepada masyarakat dalam bentuk webinar ini mampu meningkatkan pengetahuan peserta akan konsumsi sayur. Jumlah peserta yang mengikuti webinar ini sebanyak 85 peserta dari berbagai profesi. Berdasarkan kuesioner yang diberikan, terdapat peningkatan pengetahuan konsumsi sayur para peserta. Hasil ini menunjukkan bahwa pendidikan gizi yang diselenggarakan melalui daring dapat meningkatkan pengetahuan gizi masyarakat sehingga dapat menjadi alternatif pemberian informasi-informasi kesehatan lain dalam masa pandemi covid-19. Penulis menyarankan agar kegiatan pendidikan gizi terkait konsumsi sayur perlu dilaksanakan lagi secara berkelanjutan dengan peserta sasaran yang berbeda.

\section{Ucapan Terimakasih}

Penulis mengucapkan terima kasih kerjasama dan dukungan dari Healthy Plate Yogyakarta. Selain itu, penulis juga berterima kasih kepada LPPM Universitas Singaperbangsa Karawang atas pembiayaan penuh kegiatan pengabdian kepada masyarakat ini.

\section{Daftar Pustaka}

Atmadani, R. N., Yunita, S. L., Hidayati, I. R., Aldila, A. O., \& Rizqi, F. D. (2021). Penyuluhan Perilaku Hidup Bersih dan Sehat (PHBS) sebagai Upaya Preventif dalam Memutus Rantai Penyebaran Covid-19 pada kalangan Mahasiswa Baru Farmasi. To Maega: Jurnal Pengabdian Masyarakat, 4(2), 153. https://doi.org/10.35914/tomaega.v4i2.620

Balitbangkes. (2014). Studi Diet Total : Survei Konsumsi Makanan Individu.

Balitbangkes. (2018). Laporan_Nasional_RKD2018_FINAL.pdf. In Badan Penelitian dan Pengembangan Kesehatan (p. 198). http://labdata.litbang.kemkes.go.id/images/download/laporan/RKD/2018/Lap oran_Nasional_RKD2018_FINAL.pdf

Clark, M. J., \& Slavin, J. L. (2013). The effect of fiber on satiety and food intake: A systematic review. Journal of the American College of Nutrition, 32(3), 200-211. https://doi.org/10.1080/07315724.2013.791194

Gan, Y., Tong, X., Li, L., Cao, S., Yin, X., Gao, C., Herath, C., Li, W., Jin, Z., Chen, Y., \& Lu, Z. (2015). Consumption of fruit and vegetable and risk of coronary heart disease: A meta-analysis of prospective cohort studies. International Journal of Cardiology, 183, 129-137. https://doi.org/10.1016/j.ijcard.2015.01.077

Hariati, N. W. (2021). Determinan Masalah Gizi Remaja di Pondok Pesantren 
[ 90 ] Linda Riski Sefrina \& Al Mukhlas Fikri / To Maega : Jurnal Pengabdian Masyarakat, Vol.5; No.1; Februari 2022

Tebuireng (Studi Kualitatif). Jurnal Ilmiah Kesehatan, 3(2), 86-98. https://doi.org/10.36590/jika.v3i2.152

He, K., Hu, F. B., Colditz, G. A., Manson, J. E., Willett, W. C., \& Liu, S. (2004). Changes in intake of fruits and vegetables in relation to risk of obesity and weight gain among middle-aged women. International Journal of Obesity, 28(12), 1569-1574. https://doi.org/10.1038/sj.ijo.0802795

Kemenkes. (2014). PMK No. 41 Tahun 2014 tentang Pedoman Gizi Seimbang. Kementerian Kesehatan RI, 97.

Khomsan, A., Anwar, F., \& Mudjajanto, E. S. (2009). Pengetahuan, Sikap, Dan Praktek Gizi Ibu Peserta Posyandu. Jurnal Gizi Dan Pangan, 4(1), 33. https://doi.org/10.25182/jgp.2009.4.1.33-41

Mulyani, I., Dieny, F. F., Rahadiyanti, A., Fitranti, D. Y., Tsani, A. F. A., \& Murbawani, E. A. (2020). Efek motivational interviewing dan kelas edukasi gizi berbasis instagram terhadap perubahan pengetahuan healthy weight loss dan kualitas diet mahasiswi obesitas. Jurnal Gizi Klinik Indonesia, 17(2), 53. https://doi.org/10.22146/ijcn.53042

Power, M., \& St-Jacques, A. (2014). The Graduate Virtual Classroom Webinar: A Collaborative and Constructivist Online Teaching Strategy. Journal of Online Learning and Teaching, 10(4), 681.

Saraswati, I., \& Dieny, F. F. (2012). Perbedaan Karakteristik Usia, Asupan Makanan, Aktivitas Fisik, Tingkat Sosial Ekonomi Dan Pengetahuan Gizi Pada Wanita Dewasa Dengan Kelebihan Berat Badan Antara Di Desa Dan Kota. Journal of Nutrition College, 1(1), 280-291. https://doi.org/10.14710/jnc.v1i1.726

Siahaan, S. C., \& Yuwono, N. (2021). Pendidikan Dini Prinsip Edukasi Kesehatan Gizi Seimbang melalui metode Kids Play and Care. To Maega: Jurnal $\begin{array}{lll}\text { Pengabdian } \quad \text { Masyarakat, } & 4(2), & \end{array}$ https://doi.org/10.35914/tomaega.v4i2.743

Spronk, I., Kullen, C., Burdon, C., \& O’Connor, H. (2014). Relationship between nutrition knowledge and dietary intake. British Journal of Nutrition, 111(10), 1713-1726. https://doi.org/10.1017/S0007114514000087

Vergnaud, A., Norat, T., Romaguera, D., Mouw, T., May, A. M., Romieu, I., Freisling, H., Slimani, N., Morois, S., Kaaks, R., Teucher, B., Boeing, H., Buijsse, B., Tjønneland, A., Halkjær, J., Overvad, K., Jakobsen, M. U., Rodrı, L., Amiano, P., ... Peeters, P. H. M. (2012). Fruit and vegetable consumption and prospective weight change in participants of the European Prospective Investigation into Cancer and Nutrition - Physical Activity, Nutrition, Alcohol, Cessation of Smoking, Eating Out of Home, and Obesity study 1 -. 184-193. https://doi.org/10.3945/ajcn.111.019968

WHO. (2021). World Health Statistics 2021. 